\title{
Efficacy of Fluazinam in Suppression of Monosporascus cannonballus, the Causal Agent of Sudden Wilt of Melons
}

\author{
R. Cohen, Department of Vegetable Crops, Newe Ya'ar Research Center, Agricultural Research Organization, \\ Ramat Yishay, Israel; S. Pivonia, 'Arava Research and Development, Sapir Center 86825 Israel; D. Shtienberg, \\ Department of Plant Pathology, Institute of Plant Protection, Agricultural Research Organization, Bet Dagan 50-250 \\ Israel; M. Edelstein, and D. Raz, Department of Vegetable Crops, Newe Ya'ar Research Center; Z. Gerstl, Insti- \\ tute of Soils, Water and Environmental Sciences, The Volcani Center, Agricultural Research Organization, Bet \\ Dagan 50-250 Israel; and J. Katan, Department of Plant Pathology and Microbiology, Faculty of Agricultural, \\ Food and Environmental Quality Sciences, Hebrew University, Rehovot 76100 Israel
}

\begin{abstract}
Cohen, R., Pivonia, S., Shtienberg, D., Edelstein, M., Raz, D., Gerstl, Z., and Katan, J. 1999. Efficacy of fluazinam in suppression of Monosporascus cannonballus, the causal agent of sudden wilt of melons. Plant Dis. 83:1137-1141.

Sudden wilt (vine decline) of melon, caused by Monosporascus cannonballus, is a worldwide problem in arid and semi-arid regions. Soil disinfestation by fumigation with methyl bromide before planting is a common treatment for disease management but, because methyl bromide is expected to be banned from use within the next 10 years, alternative measures for disease suppression are needed. The efficacy of 29 fungicides against $M$. cannonballus was evaluated in vitro. Among the fungicides tested, fluazinam and kresoxim methyl were the most effective and both totally inhibited the growth of $M$. cannonballus in culture at concentrations of $10 \mu \mathrm{g}$ a.i $/ \mathrm{ml}$. Because fluazinam also was effective in inhibition of Pythium aphnidermatum, which also may be involved in sudden wilt syndrome, and kresoxim methyl was not, fluazinam was chosen for further tests. The effective dose of fluazinam for $M$. cannonballus that reduced mycelial growth by $50 \%$ was $0.09 \mu \mathrm{g}$ a.i./ml. Fluazinam efficacy was evaluated in three field experiments conducted in the spring and in the late summer cropping seasons. In two of the experiments, applications of fluazinam resulted in approximately $87 \%$ wilt reduction, whereas in the third experiment it was only $32 \%$. The mobility of fluazinam in soil was determined in samples taken from the field. Fungicide mobility in soil was relatively limited; most of the compound was adsorbed to soil particles, resulting in a zone of high concentration that decreased with depth and distance from the application site. Nevertheless, rates measured even at a depth of 25 $\mathrm{cm}$ were sufficient to control $M$. cannonballus. This study shows that fluazinam may be used as one component in an integrated approach for suppression of sudden wilt of melons.
\end{abstract}

Additional keywords: chemical control, Cucumis melo, integrated pest management

Sudden wilt of melon (Cucumis melo), also known as "melon collapse" and "vine decline," is a worldwide problem (15). The syndrome is particularly important in arid and semi-arid regions such as the "Arava region in southern Israel. Sudden wilt and the involvement of Monosporascus cannonballus in the disease have been reported from the southern United States, Central America, Japan, Tunisia, Saudi Arabia, and Spain $(2,7,9,13,14,16-18,27)$. The disease causes a rapid wilt of plants bearing mature

Corresponding author: R. Cohen

E-mail: ronico@netvision.net.il

Contribution no. 149-99 series, from the Agricultural Research Organization, Newe Ya'ar Research Center, Agricultural Research Organization P.O.B. 1021, Ramat Yishay, Israel.

Accepted for publication 3 September 1999.

Publication no. D-1999-1020-02R

(C) 1999 The American Phytopathological Society
Methyl bromide is expected to be banned from use within the next 10 years (in the United States by the year 2001 and in Israel and elsewhere by the year 2010; 23). Accordingly, alternative measures for disease suppression are urgently needed. It is possible that some fungicides may be effective against $M$. cannonballus but, to the best of our knowledge, such efficacy has not yet been identified. In general, control of soilborne pathogens with fungicides is more complicated and less successful than chemical control of foliar diseases (24). The behavior of a fungicide in soil depends on the physical, chemical, and biological properties of both the soil and the fungicide used. Processes such as sorption, degradation, mobility, penetration into the host tissue, and translocation within the plant determine the activity of a compound and its residual life in soil (24). The objective of the present study was to identify fungicides with high efficacy against $M$. cannonballus in culture and to test their activity under field conditions. A brief report with partial results has been published (4).

\section{MATERIALS AND METHODS}

Inhibition of $M$. cannonballus in culture. The activity of 29 different fungicides against $M$. cannonballus was determined in vitro (Table 1). Sterile aqueous solutions of the fungicides were mixed with melted yeast extract-glucose agar medium to give a concentration of $10 \mu \mathrm{g}$ a.i./m. A $12-\mathrm{mm}$ disk of agar with $M$. cannonballus mycelia from a 10-day-old culture was placed in the center of the petri dishes containing the compound-amended agar. The dishes were incubated at $27^{\circ} \mathrm{C}$ for 5 days, after which the colony diameter was measured in two perpendicular directions and its area calculated. The inhibition of mycelial growth was determined in relation to that of the control (without fungicide) treatment. There were four replicates (petri dishes) for each compound and the test was repeated once. Fungicides that were highly effective in this set of experiments were used in further tests. In the second set of trials, dose-response curves were used to determine the effective dos- 
ages that reduce mycelial growth by $50 \%$ $\left(E D_{50}\right)$. A series of decreasing concentrations of the fungicides were prepared in water. Yeast extract-glucose agar was amended with the test compounds at concentrations ranging from 10 to $0.01 \mu \mathrm{g}$ a.i./ml. $\mathrm{ED}_{50}$ was calculated from the regression equation of the log-probit transformed dose-response curves. There were four replicates (petri dishes) for each compound concentration and the test was repeated once.

Management of M. cannonballus in field tests. The efficacy of the fungicide fluazinam (Trade name-Frowncide, Ohayo, $50 \%$ soluble concentrate, produced by ISK, Japan) in suppression of $M$. cannonballus was determined in three field experiments conducted in the 'Arava region of Israel. The first experiment was conducted in spring 1996 (transplanted in February) and the second and third in late summer (transplanted in the September cropping of 1996 and 1997). These are the two common cropping seasons for melon in the 'Arava. In all experiments, the susceptible melon cultivar Galia was used. In the first experiment, the soil was infested artificially. Plastic cylinders with open ends, 30 $\mathrm{cm}$ in diameter and $35 \mathrm{~cm}$ long, were filled with field soil and buried flush with the soil surface in beds. The distance between cylinders within rows was $50 \mathrm{~cm}$ and intrarow spacing was $160 \mathrm{~cm}$. Drip irrigation tubes were placed on the beds and the beds

Table 1. In vitro growth inhibition of Monosporascus cannonballus by 29 fungicides at 10 $\mu \mathrm{g}$ a.i. $/ \mathrm{ml}^{\mathrm{a}}$

\begin{tabular}{lc}
\hline Fungicide tested & $\begin{array}{c}\text { Growth } \\
\text { inhibition }(\boldsymbol{\%})\end{array}$ \\
\hline Benomyl & 98.4 \\
Carbendazim & 95.7 \\
Carbendazim + diethofencarb & 52.1 \\
Dichlofluanid & 66.5 \\
Dicloran & 40.4 \\
Diniconazole & 77.5 \\
Fenarimol & 66.5 \\
Flutriafol & 0 \\
Fluazinam & 100 \\
Flusufamid & 40.4 \\
Hexaconazole & 77.5 \\
Imazalil sulfate & 66.5 \\
Iprodione & 66.5 \\
Kreoxin methyl & 100 \\
Maneb & 83.2 \\
Mertiram & 93.1 \\
Myclobutanil & 52.1 \\
Oxycarboxin & 40.4 \\
Paclobutrazol & 40.4 \\
Polyoxin AL & 0 \\
Polyoxin B & 66.5 \\
Quinomethionate & 83.2 \\
Quintozene & 66.5 \\
TCMTB & 89.8 \\
Thiophanate methyl & 66.5 \\
Tolclofos methyl & 83.2 \\
Tolclofos methyl + thiram & 0 \\
Triadimenol & 0 \\
Uniconazol & 0 \\
\hline aycelitg & \\
\hline
\end{tabular}

a Mycelial growth inhibition was obtained on fungicide-amended medium. were then covered manually with plastic sheets (Polyon, Barqay, Israel). Methyl bromide (Dead Sea Bromine Group, Be'er Sheva', Israel) was applied through the irrigation tubes at a rate of $50 \mathrm{~g} / \mathrm{m}^{2}$, employing a hot gas method (11). After fumigation, the soil content of the cylinders was infested with $M$. cannonballus. An isolate of $M$. cannonballus obtained from a wilted melon plant was grown for 10 days on potato dextrose agar (PDA) at $27^{\circ} \mathrm{C}$. The content of one petri dish culture was blended with $100 \mathrm{ml}$ of sterile water and mixed with 10 liters of the methyl bromide-treated soil taken from the cylinders. In addition, $5 \mathrm{~g}$ of a mixture of soil and inoculated oats, prepared according to Mertely et al. (17), was added to the same soil. After infestation, the soil was returned to the cylinders.

Melon plants were transplanted on 13 February 1996, two plants per cylinder. Fluazinam $(0.25 \mathrm{~g}$ a.i $/ \mathrm{ml}$.) was applied to each cylinder as a soil drench in $500 \mathrm{ml}$ of water. The experiment consisted of four treatments: (i) untreated control; (ii) application of fluazinam once, 2 days after planting; (iii) application of fluazinam once, 64 days after planting; and (iv) application of fluazinam twice, 2 and 64 days after planting. Each experimental plot consisted of eight cylinders in one row. There were four replicates and treatments were arranged in a randomized block design. The crop was irrigated, fertilized, and maintained according to the recommendations for melon production in the 'Arava region.

The second and third experiments were conducted in naturally infested soil at the 'En Tamar Experiment Station, located at the northern part of the "Arava. Melon plants were transplanted on 17 September 1996 and 15 September 1997. Intra-row spacing was $50 \mathrm{~cm}$ and beds were $190 \mathrm{~cm}$ apart. The second experiment consisted of five treatments: (i) untreated control; (ii) application of fluazinam at a rate of $750 \mathrm{~g}$ a.i./ha at 12, 24, 36, and 48 days after planting; (iii) application of fluazinam at a rate of $1,500 \mathrm{~g}$ a.i./ha at $12,24,36$, and 48 days after planting; (iv) application of fluazinam at a rate of $1,500 \mathrm{~g}$ a.i./ha starting 7 days after planting and continuing at 7-day intervals for a total of eight applications; and (v) application of fluazinam at a rate of $1,500 \mathrm{~g}$ a.i./ha twice, 12 and 48 days after planting. Fluazinam was applied in all treatments as a soil drench in $400 \mathrm{ml}$ of water/plant. Each experimental plot was $5 \mathrm{~m}$ long; there were four replicates per treatment, and treatments were arranged in a randomized complete block design.

In the third experiment, plots were either not treated or treated with fluazinam at a rate of $750 \mathrm{~g}$ a.i./ha, four times during the season. The fungicide was applied through the drip irrigation system starting 10 days after transplanting and continuing at biweekly intervals. Experimental plots were
$7 \mathrm{~m}$ long and consisted of 14 transplants per plot. There were four replicates per treatment and experiments were arranged in a randomized complete block design.

Wilt was evaluated visually in all experiments. A plant was considered dead when the whole plant exhibited irreversible wilt symptoms. The number of wilted plants and the total number of plants per plot were used to calculate the incidence of wilting (percent). In the first and third experiments, wilt incidence was recorded visually upon fruit ripening. In the second experiment, wilt was evaluated $30,42,47$, and 57 days after planting. In addition, the presence of $M$. cannonballus in roots of wilted plants from the untreated plots was confirmed. Roots of wilted melon plants were stored in a paper bag in the lab for 3 weeks. The presence of $M$. cannonballus perithecia was visually evaluated.

Mobility of fluazinam in soil. The mobility of fluazinam in soil was evaluated in samples taken from the field and in vitro tests. Soil samples were taken from treatment number iv of the second experiment, 60 days after planting (after seven applications of fluazinam). Soil cores were obtained by inserting a metal tube $(4 \mathrm{~cm}$ in diameter and $25 \mathrm{~cm}$ long) into the moist soil at a distance of $10 \mathrm{~cm}$ from a plant and removing it intact with the soil sample. The cores were brought to the laboratory where they were frozen $\left(-18^{\circ} \mathrm{C}\right)$ until analysis. The cores were extruded from the metal tubes after minimal defrosting by applying air pressure to the tube. The cores were then sectioned and sub-samples taken for determination of moisture content and fungicide. Soil samples were extracted with water and ethyl acetate in a 1:1 ratio (4 ml each) overnight on a reciprocal shaker. After centrifugation to separate the phases, the organic phase was removed and stored in autosampler vials containing $\mathrm{Na}_{2} \mathrm{SO}_{4}$ to remove any residual water. The samples were analyzed on a Perkin-Elmer Autosystem gas chromatograph equipped with a nitrogen-phosphorus detector. A standard curve of fluazinam was used for quantitation.

The mobility of fluazinam in soil also was tested in vitro using a thin-layer chromatography (TLC) method (8). Clean glass plates $(20$ by $20 \mathrm{~cm})$ were coated with sieved (approximately $0.25 \mathrm{~mm}$ ) 'Arava soil, prepared as a 2:1 soil:water slurry. A TLC applicator was used for the coating procedure, producing a soil layer approximately $0.75 \mathrm{~mm}$ thick. Soil TLC plates were air dried and fluazinam solution was applied at marked spots $1.5 \mathrm{~cm}$ above the plate base. The final rate of fluazinam at each spot was $0.5,5$, and $50 \mu \mathrm{g}$. The plates were placed in a closed glass chamber containing distilled water and with a watersaturated atmosphere. The plate was removed from the chamber and air dried when the water front reached a height of $10 \mathrm{~cm}$. Spores of the fungus Cladosporium 
sp., found to be sensitive to fluazinam in preliminary tests, served as a bioassay organism and were sprayed on the soil TLC plates. Spore suspensions were prepared by flooding a Cladosporium sp. culture with $10 \mathrm{ml}$ of potato dextrose broth and scraping the medium surface with a glass. The suspension was filtered through eight layers of cheesecloth before use. After spraying the Cladosporium sp. spores, the TLC plates were incubated in a moist chamber at $25^{\circ} \mathrm{C}$ in the dark for $24 \mathrm{~h}$. Inhibition zones of Cladosporium sp. growth were used to indicate the location of the fungicide.

Statistical analysis. Data were analyzed statistically using the Minitab software package (Minitab Inc., State College, PA). Results recorded in the field experiments were subjected to analysis of variance (ANOVA) and, when differences were significant at $P \leq 0.05$, Fisher's protected least significant difference (LSD) test was employed. Fungicide dose-response and fluazinam mobility in soil were analyzed by simple regression analysis.

\section{RESULTS}

Inhibition of $M$. cannonballus in culture. Of the 29 fungicides tested, fluazinam and kresoxim methyl were the most effective and totally inhibited the growth of $M$. cannonballus in culture at concentrations of $10 \mu \mathrm{g}$ a.i./ml (Table 1). Results of a second experiment corroborated these results. Since fluazinam also was effective in inhibition of $P$. aphanidermatum in vitro $\left(\mathrm{ED}_{50} \quad 0.33 \mu \mathrm{g} \quad \mathrm{a} . \mathrm{i} . / \mathrm{ml}\right)$, and kresoxim methyl was not (unpublished data), fluazinam was chosen for further tests. P. apha-

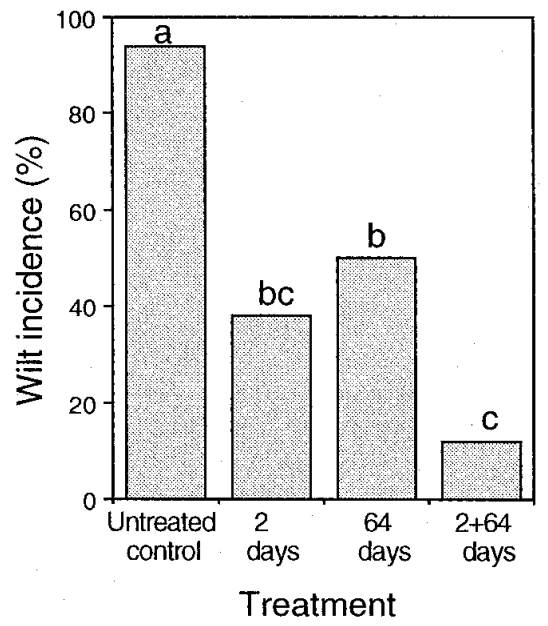

Fig. 1. Effect of the fungicide fluazinam on sudden wilt of melons caused by Monosporascus cannonballus. The experiment was conducted on artificially inoculated plants in the spring. Fluazinam $(0.25 \mathrm{~g}$ a.i./two plants $)$ was applied as a soil drench in $500 \mathrm{ml}$ of water at 2, 64 , or 2 and 64 days after transplanting. Bars followed with common letter are not significantly different $(P=0.05)$ as determined by Fisher's protected least significant difference test. nidermatum also may be involved in the sudden wilt syndrome, solely or in interaction with $M$. cannonballus $(20,21)$. The $\mathrm{ED}_{50}$ of fluazinam for $M$. cannonballus was $0.09 \mu \mathrm{g}$ a.i. $/ \mathrm{ml}$.

Management of $M$. cannonballus in field tests. Significant reduction in wilt incidence was achieved in the spring experiment in all plots treated with fluazinam (Fig. 1). One application of the fungicide, either 2 or 64 days after planting, reduced wilt incidence $(P \leq 0.05)$ by 59.6 and $46.8 \%$. Application of fluazinam twice $(2$ and 64 days after planting) resulted in the highest wilt suppression $(86.2 \%$ wilt reduction). The fungus $M$. cannonballus was isolated from roots of all sampled wilted plants, indicating that $M$. cannonballus was the cause of the sudden wilt syndrome in that trial.

In the second experiment, fluazinam was applied to a late summer cropping of melon transplants grown in a naturally infested field. Although wilt suppression was significant in some of the treatments, its magnitude was less pronounced than in the first experiment. In plots treated four times during the growing season, doubling the rate of fluazinam (from 750 to $1,500 \mathrm{~g}$ a.i./ha in each application) did not improve wilt suppression. By the end of the experiment, wilt incidence in the treated plots did not differ significantly from that of the untreated plots (Fig. 2). Increasing the frequency of applications and the resultant total number of applications (from two to four and eight applications during the growing season) improved wilt suppression at the early stages of the epidemic but, by the end of the season, there were no differences in wilt in the different fungicidetreated plots (Fig. 3).
In the third experiment, the efficacy of fluazinam was confirmed. Wilt was observed soon before ripening. In the fluazinam-treated plots, wilt incidence was $11.0 \%$, significantly lower than in the untreated plots, where wilt incidence was $93.7 \%$.

Mobility of fluazinam in soil. The mobility of fluazinam was studied in the laboratory using the soil TLC method and by analyzing soil samples taken from the second fields experiment. Both methods revealed that fluazinam mobility in soil was limited. Inhibition zones of Cladosporium sp. (the bioassay organism) on the soil TLC plates were restricted to the area of fungicide application (Fig. 4). In soil sampled from the field, exceedingly high concentrations of fluazinam were found to a depth of $4.5 \mathrm{~cm}$, after which the concentration of fluazinam diminished rapidly and only $5 \mathrm{mg} / \mathrm{kg}$ soil was recovered at a depth of $25 \mathrm{~cm}$ (Fig. 5).

\section{DISCUSSION}

The widespread and destructive nature of sudden wilt of melons caused by $M$. cannonballus constitutes a serious threat to melon cultivation in the major production areas of the world. Currently, the only means to control the disease in Israel is application of methyl bromide as a preplant soil treatment (26). The use of methyl bromide will be banned worldwide within the next 5 to 10 years (23). Thus, the development of alternative control measures is of great importance to the melon industry. Application of fungicides to the soil is a possible solution, but application prior to planting (as soil disinfestation) is more common and successful than application of fungicides during the growing season (24).

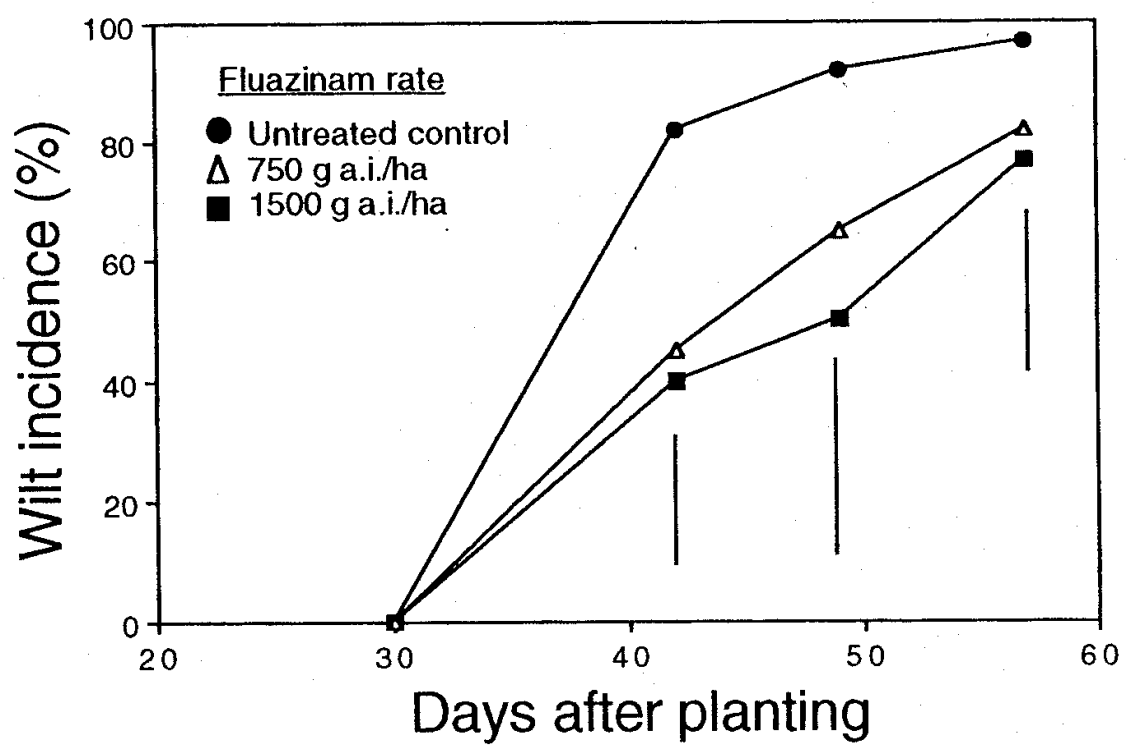

Fig. 2. Effect of the rate of the fungicide fluazinam on sudden wilt of melons caused by Monosporascus cannonballus. The experiment was conducted in the late summer season of 1996 under natural epidemics. The fungicide was applied as a soil drench (400 ml/plant), at two rates, 750 and 1,500 $\mathrm{g}$ a.i./ha, at 12, 24, 36, and 48 days after planting. Vertical bars represent the least significant difference (at $P \leq 0.05$ ) as determined by Fisher's protected least significant difference test. 


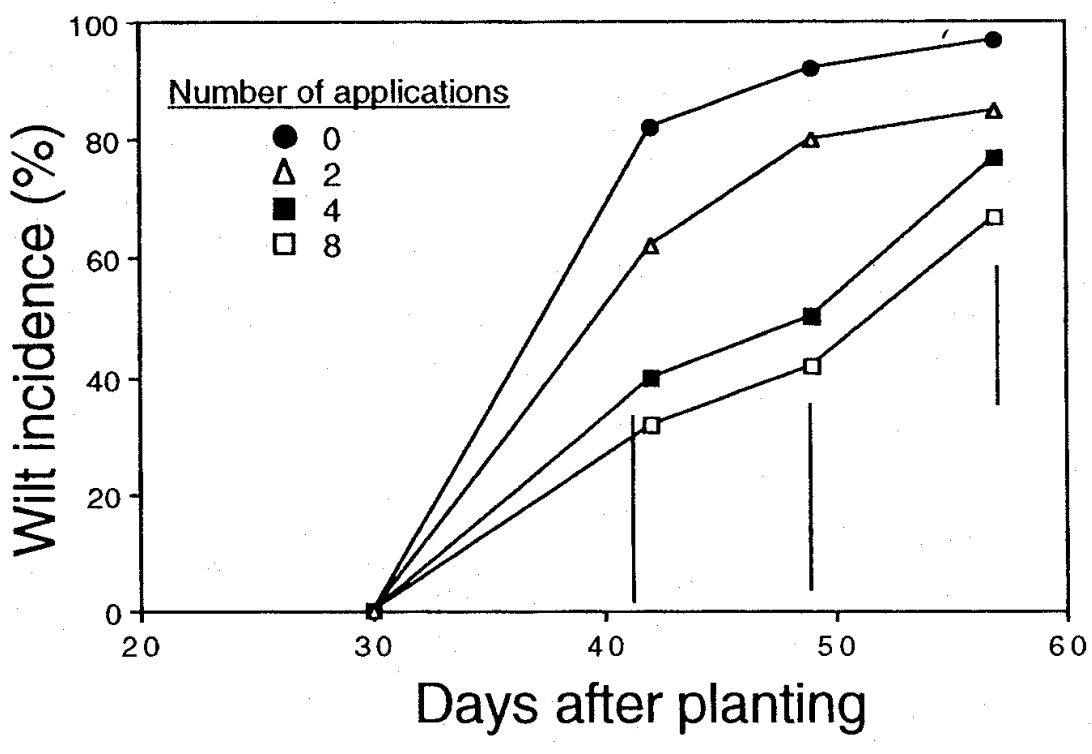

Fig. 3. Effects of the number of fluazinam applications on Monosporascus cannonballus. The experiment was conducted in the late summer season of 1996 under natural epidemics. The fungicide was applied as soil drench ( $400 \mathrm{ml} / \mathrm{plant})$, at a rate of 1,500 $\mathrm{g}$ a.i./ha at 12, 24, 36, and 48 days after planting. Vertical bars represent the least significant difference (at $P<0.05$ ) as determined by Fisher's protected least significant difference test.

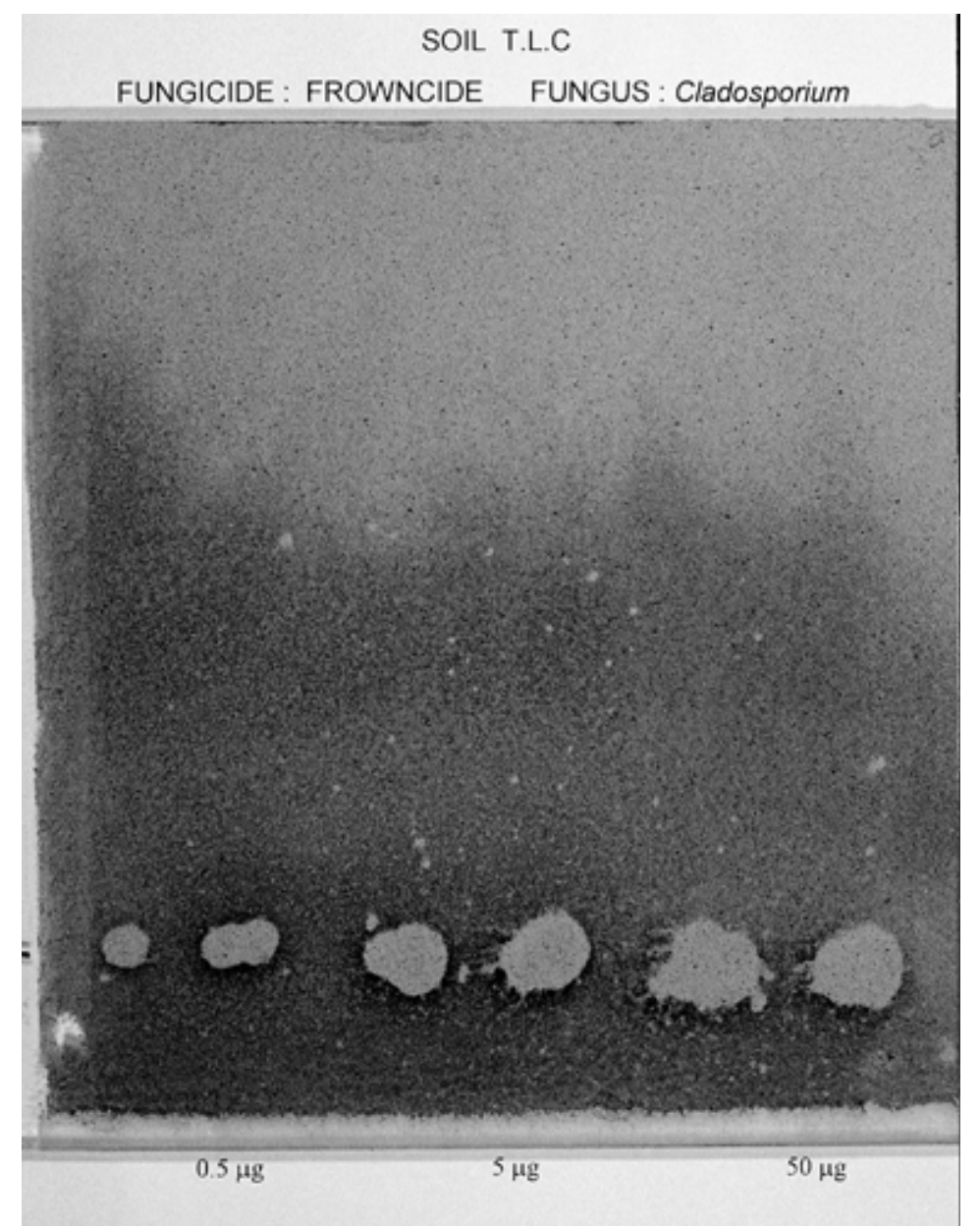

Fig. 4. Soil thin layer chromatography (TLC) plates used for determining the mobility of the fungicide fluazinam (trade name "Frowncide") in soil. Fluazinam was applied at three rates $(0.5$, 5 , and $50 \mu \mathrm{g}$ ) to soil taken from the "Arava region in southern Israel. TLC plates were sprayed with spores of a Cladosporium sp., which was used as a fungal bioassay for detecting the presence of the fungicide.
Fungicide application to existing crops is practiced mainly for management of seedling diseases such as Pythium and Rhizoctonia damping off. In these pathosystems, host-pathogen interaction occurs during a short period of time and in a relatively limited soil volume. Chemical control of pathogens that attack the deep root system or older plants, such as Fusarium, Verticillium, and Monosporascus spp., is less common, due to the complexity of the interaction. To date, practical experience for this type of pathosystem is lacking (5).

Fluazinam and kreoxim methyl both completely inhibited vegetative growth of $M$. cannonballus in culture. The in vitro tests involved inhibition of fungal mycelia. Fluazinam was chosen for further testing under field conditions because it was also effective against $P$. aphanidermatum. In the field, M. cannonballus ascospores are the primary source of infection, not mycelia. Ascospores germinate only in the rhizosphere of roots of susceptible melon cultivars in response to exudates secreted by the root (25); therefore, it was not possible to test the activity of the various fungicides in vitro on ascospores.

Fluazinam efficacy in suppression of sudden wilt was confirmed in the field, but results varied. In the first and third experiments, control at fruit ripening was approximately $87 \%$; whereas, in the second experiment, it was only $32 \%$. Variation in control may result from differences in inoculum load in soil, growing conditions, and temperature regimes that prevail during the season. Analysis of experiments conducted in the "Arava region revealed that wilt incidence is enhanced at high temperatures, especially upon ripening, where the crop may suffer from temporal water stresses $(3,20)$. Similarly, Kim et al. (10) reported that, in Arizona, infections developed earlier and wilt intensity was more severe in the late summer cropping (planted in July) than in spring cropping (planted in January to February). They also indicated that severe epidemics were associated with soil temperatures greater than $25^{\circ} \mathrm{C}(10)$.

Fluazinam efficacy also was demonstrated in a commercial field (28). The fungicide was applied via the drip irrigation system to part of a field ( 0.3 ha in size) located in 'En Tamar in the northern 'Arava region. Applications were made four times $(18,33,47$, and 61 days after planting) at a rate of $750 \mathrm{~g}$ a.i./ha. Although the entire field was fumigated prior to planting with methyl bromide, $94 \%$ of the plants had collapsed by the end of the season in the part that was not treated with fluazinam. In the part of the field that was treated with fluazinam, wilt incidence was $4 \%$. As indicated above, methyl bromide does not always provide adequate disease suppression in commercial situations.

Soil TLC and field soil analysis reveled that fluazinam mobility in soil is limited 


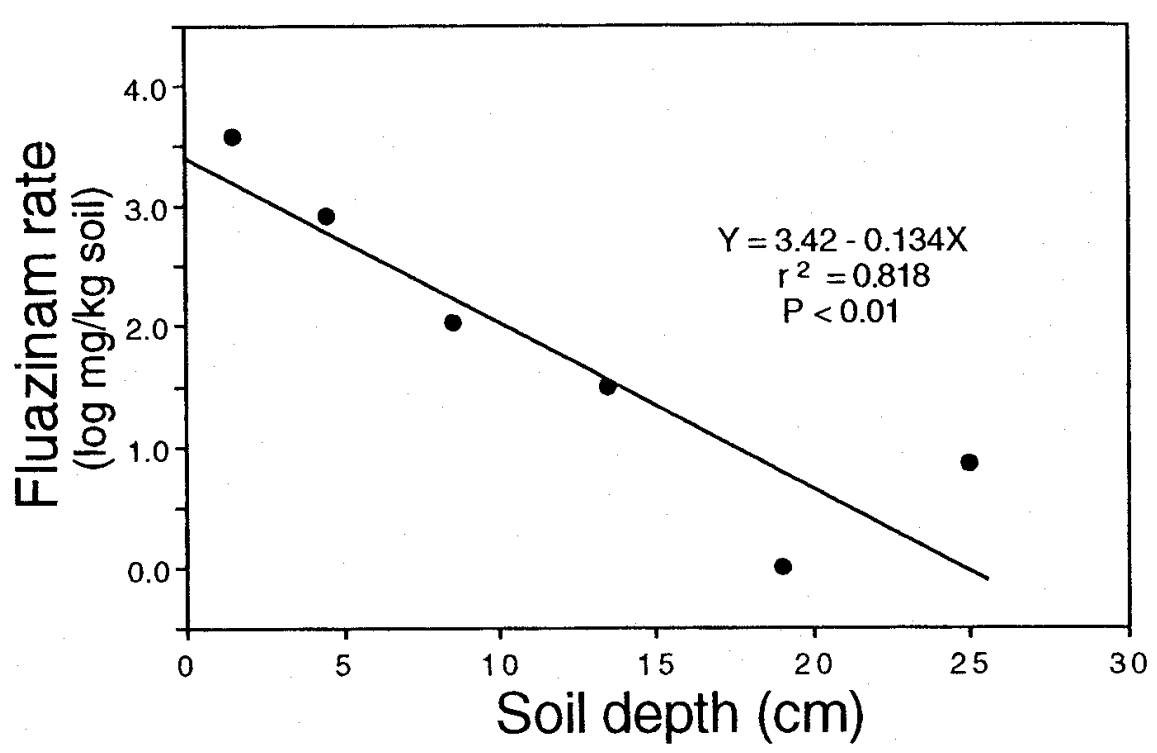

Fig. 5. Fluazinam distribution in field soil profile. Samples were taken from late-summer experiments. Fluazinam was applied as drench seven times, at a rate of 1,500 $\mathrm{g}$ a.i./ha.

(Figs. 4 and 5). When applied in water, most of the fungicide is absorbed in the soil surface layer, resulting in a zone of high rate of the compound, and decreasing concentrations with depth and distance from the application site. Nevertheless, rates measured even at a depth of $25 \mathrm{~cm}$ were sufficient to control $M$. cannonballus (Fig. 5). It may be possible that applications that result in a more even distribution of the fungicide in soil would further improve control efficacy.

The present study shows, for the first time, that sudden wilt caused by $M$. cannonballus may be managed by post-planting applications of a fungicide. However, control efficacy was inadequate in some cases and varied among experiments; therefore, more research is needed before fluazinam can be used commercially for disease suppression. Nevertheless, even when the rate and application method of fluazinam are optimized, it should not be used as a sole measure for disease suppression. Instead, it should be incorporated as a component in an integrated management approach. Such an approach also may involve the use of resistant or tolerant melon cultivars, transplanting of grafted melon plants, and reduction of initial inoculum load in the soil.

\section{LITERATURE CITED}

1. Alcantara, T. P., Rasmussen, S. L., and Stanghellini, M. E. 1997. Biological characterization of Monosporascus cannonballus. (Abstr.) Phytopathology 87:S3.

2. Bruton, B. D. 1997. Occurrence of vine decline disease on muskmelon in Guatemala.
Plant Dis. 81:694.

3. Cohen, R., Elkind, Y., Burger, Y., Offenbach, R., and Nerson, H. 1996. Variation in the response of melon genotypes to sudden wilt. Euphytica 87:91-95.

4. Cohen, R., Pivonia, S., Shtienberg, D., Raz, D., Shriber, S., Gerrstel, Z., and Katan, J. 1997. Chemical control of Monosporascus, the causal agent of the root rot and vine decline disease of melons. (Abstr.) Phytoparasitica 25:255.

5. Erwin, D. C. 1981. Chemical control. Pages 563-594 in: Fungal Wilt Diseases of Plants. M. E .Mace, A. A. Bell, and C. H. Beckman. eds. Academic Press, New York.

6. Eyal, H., and Cohen, Y. 1986. Sudden wilt in muskmelon: a continuing challenge. (Abstr.) Phytoparasitica 14:251.

7. Garcia-Jimenez, J., Velazquez, M. T., Jorda, C., and Alfaro-Garcia, A. 1994. Acremonium species as the causal agent of muskmelon collapse in Spain. Plant Dis. 78:416-419.

8. Helling, C. S., Dennison, D. Gayle, and Kaufman D. D. 1974. Fungicide movement in soil. Phytopathology 64:1091-1100.

9. Karlatti, R. S., Abdeen, F. M., and Al-Fehaid, M. S. 1997. First report of Monosporascus cannonballus on melons in Saudi Arabia. Plant Dis. 81:1215.

10. Kim, D. H., Rasmussen, S. L., and Stanghellini, M. E. 1995. Monosporascus cannonballus root rot of muskmelon: Root infection and symptoms development in relation to soil temperature. (Abstr.) Phytopathology 85:1195.

11. Klein, L. 1996. Methyl bromide as soil fumigant. Pages 191-235 in: The Methyl Bromide Issue. C. H. Be, N. Price, and B. Chakrabarti, eds. John Wiley \& Sons, New York.

12. Krikun, J. 1985. Observations on the distribution of the pathogen Monosporascus eutypoides as related to soil temperature and fertilization. Phytoparasitica 13:225-228.

13. Martyn, R. D., Lovic, B. R., Maddox, D. A., Germash, A., and Miller, M. E. 1994. First re- port of Monosporascus root rot/vine decline of watermelon in Tunisia. Plant Dis. 78:1220.

14. Martyn, R. D., and Miller, M. E. 1996. Monosporascus root rot and vine decline of muskmelon and watermelon. Pages 18-19 in: Compendium of Cucurbit Diseases. T. A. Zitter, D. L. Hopkins, and C. E. Thomas, eds. American Phytopathological Society, St. Paul, MN.

15. Martyn, R. D., and Miller, M. E. 1996. Monosporascus root rot and vine decline, an emerging disease of melons worldwide. Plant Dis. 80:716-725.

16. Mertely, J. C., Martyn, R. D., Miller, M. E., and Bruton, B. D. 1991. Role of Monosporascus cannonballus and other fungi in root rot/vine decline disease of muskmelon. Plant Dis. 75:1133-1137.

17. Mertely, J. C., Martyn, R. D., Miller, M. E., and Bruton, B. D. 1993. An expanded host range for the muskmelon pathogen Monosporascus cannonballus. Plant Dis. 77:667-673.

18. Miller, M. E., Martyn, R. D., Lovic, B. R., and Bruton, B. D. 1995. An overview of vine decline diseases in melons. Pages 31-35 in: Proc. Cucurbitaceae 94: Evaluation and Enhancement of Cucurbit Germplasm. G. E. Lester and J. R. Dunlap, eds. Gateway Printing, Edinburgh, TX

19. Pivonia, S., Cohen, R., Kafkafi, U., Ben Ze'ev, I. S., and Katan, J. 1997. Sudden wilt of melons in southern Israel: Fungal agents and relationship with plant development. Plant Dis. 81:1264-1268.

20. Pivonia, S., Cohen, R., Katan, J., Ben Zeev, I. S., and Kafkafi, U. 1996. Phytopathological and physiological aspects of sudden wilt of melons in the Arava region. (Abstr.) Phytoparasitica 24:142.

21. Pivonia, S., Cohen, R., Katan, J., Burger, Y., Ben Ze'ev, I. S., Karchi, Z., and Edelstein, M. 1996. Sudden wilt of melons in Southern Israel. Pages 285-290 in: Proc. VIth Eucarpia Meet. Cucurbit Genet. Breed. Malaga, Spain.

22. Reuveni, R., Krikun, J., and Shani, U. 1983. The role of Monosporascus eutypoides in a collapse of melon plants in the arid area of Israel. Phytopathology 73:1223-1226.

23. Ristaino, J. B., and Thomas, W. 1997. Agriculture, methyl bromide and the ozone hole, can we fill the gap. Plant Dis. 81:964-977.

24. Shnha, A. P., Singh, K., and Mukhopadhyay, A. N. 1988. Soil Fungicide. CRC Press, Inc. Boca Raton, FL.

25. Stanghellini, M. E., Kim, D. H., and Rasmussen, S. L. 1996. Ascospores of Monosporascus cannonballus: Germination and distribution on cultivated and desert soils in Arizona. Phytopathology 86:509-514.

26. Ucko, O., Maduel, A., Grinstein, A., and Katan, J. 1992. Combined methods of soil disinfestation for controlling melon collapse with reduced methyl bromide dosages. (Abstr.) Phytoparasitica 20:229-230.

27. Uematsu, S., Hirota, K., Shiruishi, T., Ooizumi, T. Sokiyama, K., Ishikura, I., and Edagowa, Y. 1992. Monosporascus root rot on bottle gourd stock of watermelon caused by Monosporascus cannonballus. Ann. Phytopathol. Soc. Jpn. 58:354-359.

28. Yogev, E., Zehavi, T., Ben-Arie, R., and Alon, P. U. 1997. Ohayo (fluazinam), a fungicide for the control of Botrytis and soil diseases. (Abstr.) Phytoparasitica 25:249. 